\title{
Characterisation and airborne deployment of a new counterflow virtual impactor inlet
}

\author{
T. Shingler ${ }^{1}$, S. Dey ${ }^{2}$, A. Sorooshian ${ }^{1,3}$, F. J. Brechtel ${ }^{2}$, Z. Wang ${ }^{1}$, A. Metcalf ${ }^{4}$, M. Coggon ${ }^{4}$, J. Mülmenstädt $^{5}$, \\ L. M. Russell ${ }^{5}$, H. H. Jonsson ${ }^{6}$, and J. H. Seinfeld ${ }^{4}$ \\ ${ }^{1}$ Department of Chemical and Environmental Engineering, University of Arizona, P.O. Box 210011, Tucson, \\ Arizona, 85721, USA \\ ${ }^{2}$ Brechtel Manufacturing Inc., Hayward, 94544, California, USA \\ ${ }^{3}$ Department of Atmospheric Sciences, University of Arizona, P.O. Box 210081, Tucson, Arizona, 85721, USA \\ ${ }^{4}$ Departments of Environmental Science and Engineering and Chemical Engineering, California Institute of Technology, \\ Pasadena, California, USA \\ ${ }^{5}$ Scripps Institution of Oceanography, University of California, San Diego, La Jolla, California, USA \\ ${ }^{6}$ Center for Interdisciplinary Remotely-Piloted Aircraft Studies, Naval Postgraduate School, Monterey, California, USA
}

Correspondence to: A. Sorooshian (armin@email.arizona.edu)

Received: 29 January 2012 - Published in Atmos. Meas. Tech. Discuss.: 14 February 2012

Revised: 6 May 2012 - Accepted: 16 May 2012 - Published: 6 June 2012

\begin{abstract}
A new counterflow virtual impactor (CVI) inlet is introduced with details of its design, laboratory characterisation tests and deployment on an aircraft during the 2011 Eastern Pacific Emitted Aerosol Cloud Experiment (EPEACE). The CVI inlet addresses three key issues in previous designs; in particular, the inlet operates with: (i) negligible organic contamination; (ii) a significant sample flow rate to downstream instruments $\left(\sim 151 \mathrm{~min}^{-1}\right)$ that reduces the need for dilution; and (iii) a high level of accessibility to the probe interior for cleaning. Wind tunnel experiments characterised the cut size of sampled droplets and the particle size-dependent transmission efficiency in various parts of the probe. For a range of counter-flow rates and air velocities, the measured cut size was between 8.7-13.1 $\mu \mathrm{m}$. The mean percentage error between cut size measurements and predictions from aerodynamic drag theory is $1.7 \%$. The CVI was deployed on the Center for Interdisciplinary Remotely Piloted Aircraft Studies (CIRPAS) Twin Otter for thirty flights during E-PEACE to study aerosol-cloud-radiation interactions off the central coast of California in July and August 2011. Results are reported to assess the performance of the inlet including comparisons of particle number concentration downstream of the CVI and cloud drop number concentration measured by two independent aircraft probes. Measurements downstream of the CVI are also examined from one representative case flight coordinated with shipboard-emitted smoke that was intercepted in cloud by the Twin Otter.
\end{abstract}

\section{Introduction}

The aerosol nuclei that are the seeds of cloud-drops and ice are a critically important component of the atmosphere as they influence radiative transfer, visibility and cloud formation. Characterisation of the physical and chemical properties of these nuclei is needed to increase understanding of how aerosol particles affect clouds and, in turn, how clouds modify aerosol properties. Essential to understanding these interactions are properties including particle size distribution, chemical composition and hygroscopicity (Twohy et al., 1989; Hudson, 1993; Hallberg et al., 1994, 1998; Ostrom et al., 2000; Sellegri et al., 2003). Aerosol sampling from aircraft has previously relied on particle retrieval via inlets that accept all particles in the free stream, without any preferential selection for particle size. These total aerosol inlets are often unable to sufficiently decelerate the larger aerosol particles or evaporate the water residue surrounding their nuclei, typically leading to inertial deposition and droplet shatter (Huebert et al., 1990; Hudson and Frisbie, 1991; Baumgardner and Huebert, 1993; Weber et al., 1998; Hermann et al., 2001; Hegg et al., 2005). These limitations interfere with sampling a known population of aerosol in clouds, usually resulting in a mixture of interstitial aerosol particles and shattered droplets. The inlet traditionally used to sample only cloud drops is the counterflow virtual impactor (CVI), which has been discussed extensively in previous work (e.g., Ogren 
et al., 1985, 1987; Noone et al., 1988; Laucks and Twohy, 1998).

CVI inlets have undergone a number of design changes in the last three decades to increase their functionality and sampling efficiency. Initially, aircraft CVIs were deployed in a single fixed-tube construction, containing a large bend radius to channel the sample stream into an aircraft. Modifications to the original inlet lip structure and inner CVI geometry have led to increased collection efficiencies at lower particle diameters (Anderson et al., 1993; Schwarzenböck and Heintzenberg, 2000). Further enhancements include the addition of upstream shrouds to aid the alignment of the free stream with the inlet (Twohy, 1998). However, a number of issues still persist. For example, CVIs often are characterised by low sample flow rates and consequently need significant dilution flow so that a sufficient amount of air flow can be supplied to multiple instruments simultaneously. This is problematic for aircraft payloads containing multiple instruments downstream of the CVI that struggle with detection limit issues (e.g., Berg et al., 2009); for example, a particleinto-liquid sampler (PILS) typically requires approximately $12-151 \mathrm{~min}^{-1}$ of air flow, which is a significant amount of flow when sampling downstream of a CVI (Sorooshian et al., 2006a, b, 2010). Furthermore, advanced chemical composition measurement devices, such as the Aerodyne Aerosol Mass Spectrometer (AMS) are vulnerable to contamination from compounds used to fabricate some older CVI designs, including siloxane sealant (Hayden et al., 2008). Finally, access to the interior of older probe designs, especially for cleaning porous sections, can be challenging. A number of such issues have been addressed with the development of the CVI discussed in this work.

The goal of this work is to report on a new aircraftmountable CVI manufactured by Brechtel Manufacturing Inc. (BMI, Model 1204, www.brechtel.com). This manuscript will provide a detailed description of the inlet design, summarise laboratory characterisation results from wind tunnel experiments, and relate wind tunnel results to theoretical calculations of cut size behaviour using aerodynamic drag theory. Results from a recent aircraft field campaign (2011 Eastern Pacific Emitted Aerosol Cloud Experiment, E-PEACE) are presented to summarise early results and its performance, including validation of wind tunnel results for size-dependent particle transmission efficiency and droplet cut size.

\section{CVI design}

The theory of CVI operation is well-documented in previous work (Ogren et al., 1985, 1987; Lin and Heintzenberg, 1995). The CVI inlet in this work operates in the same manner with a detailed description of the air streams provided below and in Fig. 1. A stream of filtered and heated air (referred to as the add-flow), provided by a compressor (Gast; P/N:

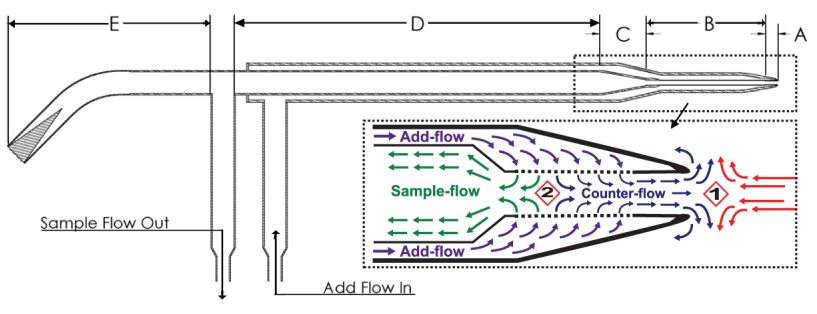

Fig. 1. Schematic depiction of the BMI CVI inlet and the flows innate to its operation (inset, not to scale). Sampled air enters the CVI through the inlet nozzle and passes through a region containing a porous tube where the heated counter-flow is introduced (A). The resulting sample flow enters an extension tube (B), before the expansion region $(C)$. (Note that the expansion angle of the diffuser between the extension tube behind the tip and the sample tube is $10.1^{\circ}$.) The particles then travel through additional plumbing (D) and enter the aircraft body for sample feed to instruments. Entities too large to bend into the aircraft are collected in a particle trap (E). Two stagnation planes (labelled 1 and 2) are generated between opposing flow directions. The cut size is governed by the velocity of the ambient air flow and the distance between the two stagnation planes.

75R635) and controlled by a mass-flow controller (MFC) (Alicat Scientific; P/N: MCP-50SLPM) used in volumetric control mode, is forced through an annular space between the exterior housing and the inner sample-stream tubing. Air is heated within this annular space and controlled with the airflow temperature measured immediately upstream of the porous section (Segment B in Fig. 1). The porous region in the inner tube is $1.02 \mathrm{~cm}$ in length and is near the tip of the inlet. The pores allow the add-flow to enter the inner sample-stream creating a counter-flow leaving the inlet, equivalent to the difference between the add-flow and sample-flow rates. The counter-flow stream is emitted outwards from the mouth of the inlet (radius $=2.3 \mathrm{~mm}$ ) and creates a stagnation plane immediately upstream of the inlet orifice (labelled 1 in Fig. 1). When sampling in cloud, small aerosol particles, lacking the inertia to penetrate the stagnation plane, are carried along the streamlines away from the orifice of the inlet. Particles capable of penetrating the exterior stagnation plane enter the orifice and pass into the opposing counter-flow within the inlet. The splitting of the addflow into the counter-flow stream and sample-flow stream creates a second stagnation plane inside the probe tip (labelled 2 in Fig. 1). Any particles decelerated to a stop before reaching the second stagnation plane return back through the inlet orifice with the counter-flow. Particles and droplets that penetrate the second stagnation plane enter the CVI sample flow. The distance created between the two stagnation planes dictates the particle cut size $\left(D_{\mathrm{p}, 50}\right)$, which is defined here as the size at which $50 \%$ of the particles are sampled by the CVI, for a specific air speed and add-flow rate.

Particles that penetrate the second stagnation plane are slowed down due to expansion of the inner tube (Segment C 
in Fig. 1), providing additional residence time to allow water associated with particles to evaporate in the heated sampleflow stream. The sample tube has an inner diameter of $27.5 \mathrm{~mm}$, resulting in an average velocity of $42 \mathrm{~cm} \mathrm{~s}^{-1}$ and Reynolds number of 765 , when operated with a sample flow rate of $151 \mathrm{~min}^{-1}$ at STP. The sample-flow stream is directed to a $90^{\circ}$ bend in the tubing and into the aircraft. Very large droplets ( $>40 \mu \mathrm{m}$ diameter) with a sufficiently high amount of inertia and long evaporation times cannot make the turn and impact in an extended region, referred to as the particle trap (Segment E in Fig. 1). The CVI in this study was optimised for a sample flow rate of $151 \mathrm{~min}^{-1}$ to accommodate the increased flow rate requirements to operate multiple instruments downstream of the inlet at the same time; as noted earlier, a limitation in previous designs was the large amount of dilution flow that needed to be added to the sample flow to provide enough sample flow to instruments. The sample stream flow rate is kept at a constant $151 \mathrm{~min}^{-1}$ by a MFC (Alicat Scientific; P/N: MCP-50SLPM) in volumetric control mode.

To address the issue of organic contamination, the inlet is constructed such that all surfaces that contact the counterflow and sample air flow are either stainless steel or aluminum. It is further noted that the tubing in Segment B of Fig. 1 is interchangeable to allow more flexibility in optimizing for different inlet cut sizes and for cleaning purposes.

\section{Laboratory characterisation}

CVI characterisation experiments were performed using the BMI wind tunnel following methods described in Anderson et al. (1993). A dispersion of hollow glass spheres (Particle diameter, $D_{\mathrm{p}}$, range $=2-20 \mu \mathrm{m}$, mean diameter $=8 \mu \mathrm{m}$, $\rho=1.1 \mathrm{~g} \mathrm{~cm}^{-3}$, Polysciences, P/N: 19823) was introduced to the wind tunnel. Beads were introduced by dropping a small quantity into a tube located above the inlet orifice at a distance of approx. $12 \mathrm{~cm}$, which is greater than the $5 \mathrm{~cm}$ stopping distance of a $20 \mu \mathrm{m}$ particle at $50 \mathrm{~m} \mathrm{~s}^{-1}$. A TSI Model 3321 Aerodynamic Particle Sizer (APS) obtained numbersize distributions sampled by the CVI inlet. Figure 2 depicts the wind tunnel sampling configuration. Turbulence intensity in the BMI wind tunnel operated at $100 \mathrm{~m} \mathrm{~s}^{-1}$ was measured using a hot-film probe (Dantec Dynamics, Model 55R01) and ranges from $4 \%(1 \sigma=3.5)$ at the perimeter to $2 \%(1 \sigma=1.5)$ at the centerline.

The glass sphere distribution introduced into the wind tunnel was sampled by the CVI operating in one of two modes: isokinetic sampling or CVI sampling. Total sampleflow drawn by the inlet was kept constant at $151 \mathrm{~min}^{-1}$ for each sampling mode. Isokinetic sampling was performed by drawing only $151 \mathrm{~min}^{-1}$ of sample flow through the inlet orifice with no add-flow, and setting the wind tunnel velocity sufficiently low to create isokinetic sampling conditions at the CVI tip. For operation in CVI sampling mode, the

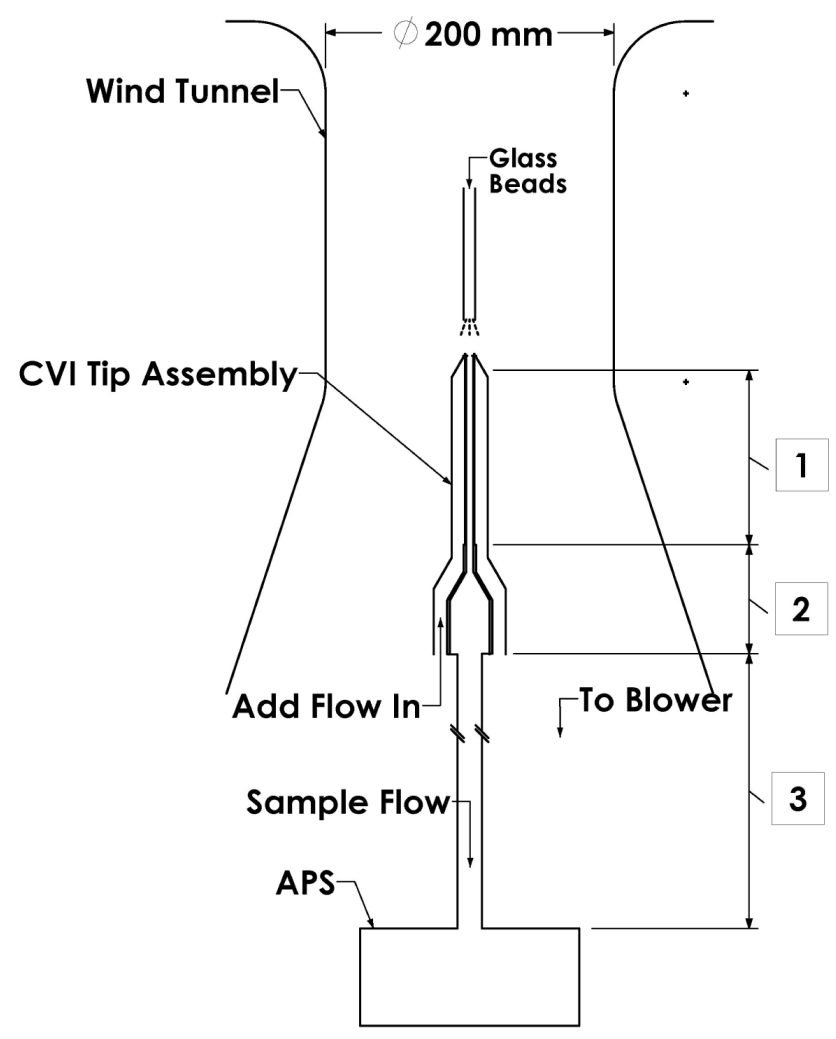

Fig. 2. Schematic of BMI wind tunnel set-up. A dispersion of glass sphere beads is introduced to the wind tunnel and the inlet operates in either isokinetic or CVI sampling mode. The ratio of the number size distributions measured by an aerodynamic particle sizer (APS) is used to determine the transmission efficiency of the inlet. These experiments followed the methods summarised by Anderson et al. (1993). The number labels are used to distinguish between different sections of the sampling train.

add-flow is supplied and the wind tunnel is run at the full desired velocity. For the characterisation experiments the tunnel was operated at two velocities: $50 \mathrm{~m} \mathrm{~s}^{-1}$ and $100 \mathrm{~m} \mathrm{~s}^{-1}$, where the former is similar to the air speed of the aircraft during E-PEACE. The add-flow rate was varied over the 16$231 \mathrm{~min}^{-1}$ range to characterise a range of cut sizes. A total of 24 trials, divided into six batches of four trials each, were performed for each of the following conditions (see also Table 1): isokinetic sampling mode and CVI sampling mode with add-flow rates of 16,19 and $231 \mathrm{~min}^{-1}$ and air speeds of 50 and $100 \mathrm{~m} \mathrm{~s}^{-1}$. Resultant counter-flow rates were 1,4 and $81 \mathrm{~min}^{-1}$, respectively.

Experimental cut size in the wind tunnel was determined by taking the ratio of the sampled CVI number-size distribution to the sampled isokinetic number-size distribution. Sampling in isokinetic mode provides a reference number-size distribution of the glass beads, to which the distribution obtained from CVI sampling mode can be compared. As described in Anderson et al. (1993), a normalisation scheme where each APS size bin is divided by the sum of counts 


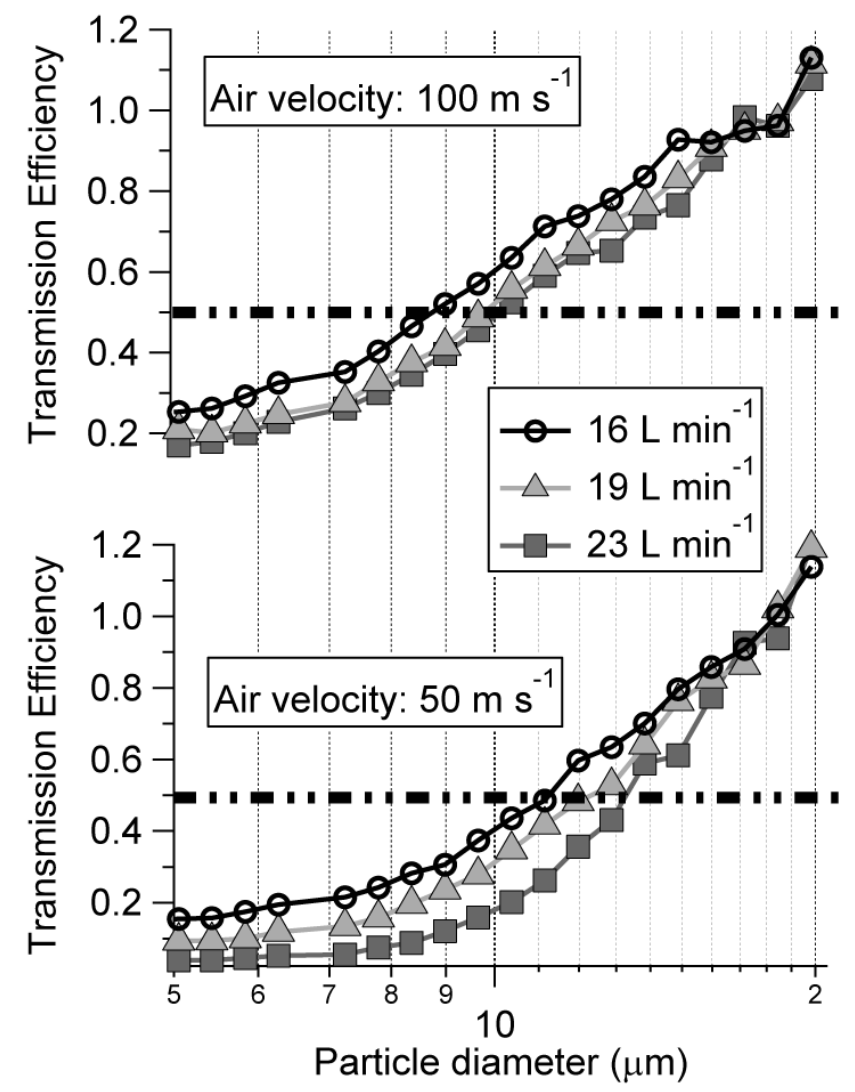

Fig. 3. Transmission efficiency of hollow glass beads at different add-flow rates based on counter-flow mode experiments conducted with the BMI wind tunnel at different air velocity conditions (50 and $100 \mathrm{~m} \mathrm{~s}^{-1}$ ). The dashed horizontal lines correspond to $50 \%$ transmission efficiency, which defines the inlet cut size $\left(D_{\mathrm{p}, 50}\right)$.

in the bins between $17-20 \mu \mathrm{m}$ was applied prior to calculating the ratio of the measured CVI number-size distribution to the reference isokinetic distribution. Stability of the numbersize distribution was evaluated by examining the variations between batch averages of the isokinetically sampled distribution. Standard deviations of the batch averages were 9 to $11 \%$ of the normalised concentration or 10 to $23 \%$ of the non-normalised concentration.

Experimentally determined cut sizes are summarised in Fig. 3 and Table 1. As expected, the cut size increased with increasing add-flow rate and decreasing wind tunnel air velocity. The cut size that corresponds to the conditions in EPEACE (air speed $=50 \mathrm{~m} \mathrm{~s}^{-1}$, add-flow rate $=161 \mathrm{~min}^{-1}$ ) is $11 \mu \mathrm{m}$. The overall range of cut sizes identified in the experiments for the range of flow conditions was 8.7-13.1 $\mu \mathrm{m}$. Previous work has defined cut sharpness as $\left(D_{\mathrm{p}, 84} / D_{\mathrm{p}, 16}\right)^{1 / 2}$, $\left( \pm 1 \sigma\right.$ about $\left.D_{\mathrm{p}, 50}\right)$ with values ranging between $1.08-1.13$ for at least one other CVI design (Anderson et al., 1993). Here we define cut sharpness as $\left(D_{\mathrm{p}, 69} / D_{\mathrm{p}, 31}\right)^{1 / 2},( \pm 0.5 \sigma$ about $\left.D_{\mathrm{p}, 50}\right)$ consistent with the higher minimum transmission efficiency below the cut size that was observed in the

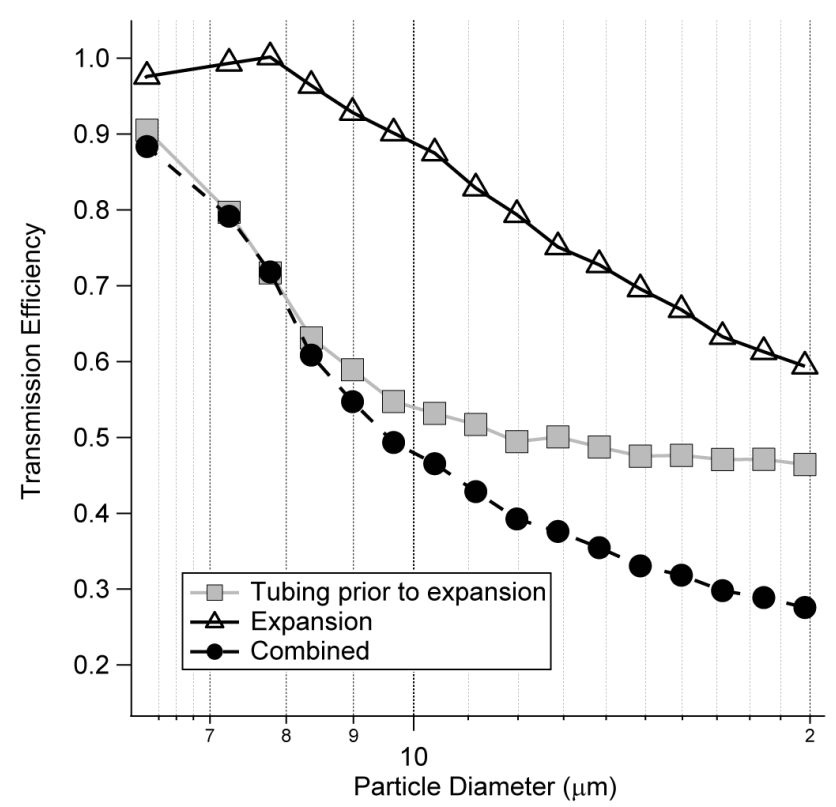

Fig. 4. Transmission efficiency for hollow glass beads through various parts of the CVI inlet based on wind tunnel experiments with the inlet not operating in counter-flow mode. The decrease in transmission efficiency is a result of various types of particle losses through each section. "Tubing prior to expansion" refers to Segment B in Fig. 1 and "Expansion" refers to Segment C in Fig. 1.

experiments. Further work will examine this minimum transmission efficiency. Table 1 shows that the modified cut sharpness values range from $1.15-1.22$ for the $50 \mathrm{~m} \mathrm{~s}^{-1}$ air speed condition and $1.28-1.34$ for $100 \mathrm{~m} \mathrm{~s}^{-1}$.

It is useful to compare the cut sizes predicted by aerodynamic drag theory to the experimentally determined values obtained in the wind tunnel experiments, as demonstrated in previous studies (e.g., Noone et al., 1988; Anderson et al., 1993). Here we adopt most of the notation and the numerical integration technique summarised by Anderson et al. (1993), where the size-dependent impaction distance is estimated between the stagnation planes using the positiondependent counter-flow gas velocity in the counter-flow region. The numerical integration is performed assuming the particle impaction starts at a distance, $L_{\text {cur }}$, away from the probe tip. The change in particle velocity is calculated along the path of impaction up to the internal stagnation plane. Particles which maintain a positive velocity through the internal stagnation plane are collected by the inlet. The theoretical cut size, $D_{\mathrm{p}, 50}$, is determined by finding the particle diameter required to have a stopping distance equal to the length of the impaction path, $L_{\mathrm{CVI}}$. The distance $L_{\mathrm{CVI}}$ is defined in Eq. (1), where $L_{\min }$ is the fixed distance from the probe tip to the start of the porous tube and $L_{\text {por }}$ is the length from the start of the porous tube to the internal stagnation plane:

$L_{\mathrm{CVI}}=L_{\mathrm{cur}}+L_{\mathrm{min}}+L_{\text {por }}$ 
Table 1. Cut size behaviour of the CVI inlet at different simulated air velocities and add-flow rates. Results are shown for wind tunnel experiments and theoretical calculations based on a numerical integration technique described by Anderson et al. (1993) using a $C_{1}$ value of 1.25. Values in parentheses in the "Measured" columns correspond to the cut sharpness defined as $\left(D_{\mathrm{p}, 69} / D_{\mathrm{p}, 31}\right)^{1 / 2}$. Values in parentheses in the "Predicted" columns signify the percent error between measured and predicted values.

\begin{tabular}{llllll}
\hline & \multicolumn{2}{c}{ Measured } & & \multicolumn{2}{c}{ Predicted } \\
\cline { 2 - 3 } \cline { 5 - 6 } $\begin{array}{l}\text { Add-flow } \\
\left(1 \mathrm{~min}^{-1}\right)\end{array}$ & $\begin{array}{l}D_{\mathrm{p}, 50} \text { at } 50 \mathrm{~m} \mathrm{~s}^{-1} \\
(\mu \mathrm{m})\end{array}$ & $\begin{array}{l}D_{\mathrm{p}, 50} \text { at } 100 \mathrm{~m} \mathrm{~s}^{-1} \\
(\mu \mathrm{m})\end{array}$ & $\begin{array}{l}D_{\mathrm{p}, 50} \text { at } 50 \mathrm{~m} \mathrm{~s}^{-1} \\
(\mu \mathrm{m})\end{array}$ & $\begin{array}{l}D_{\mathrm{p}, 50} \text { at } 100 \mathrm{~m} \mathrm{~s}^{-1} \\
(\mu \mathrm{m})\end{array}$ \\
\hline 16 & $11.0(1.22)$ & $8.7(1.34)$ & $10.8(1.8 \%)$ & $7.6(12.6 \%)$ \\
19 & $12.5(1.20)$ & $9.8(1.28)$ & & $12.9(3.2 \%)$ & $8.9(9.2 \%)$ \\
23 & $13.1(1.15)$ & $10.2(1.30)$ & $14.7(12.2 \%)$ & $10.0(2.0 \%)$ \\
\hline
\end{tabular}

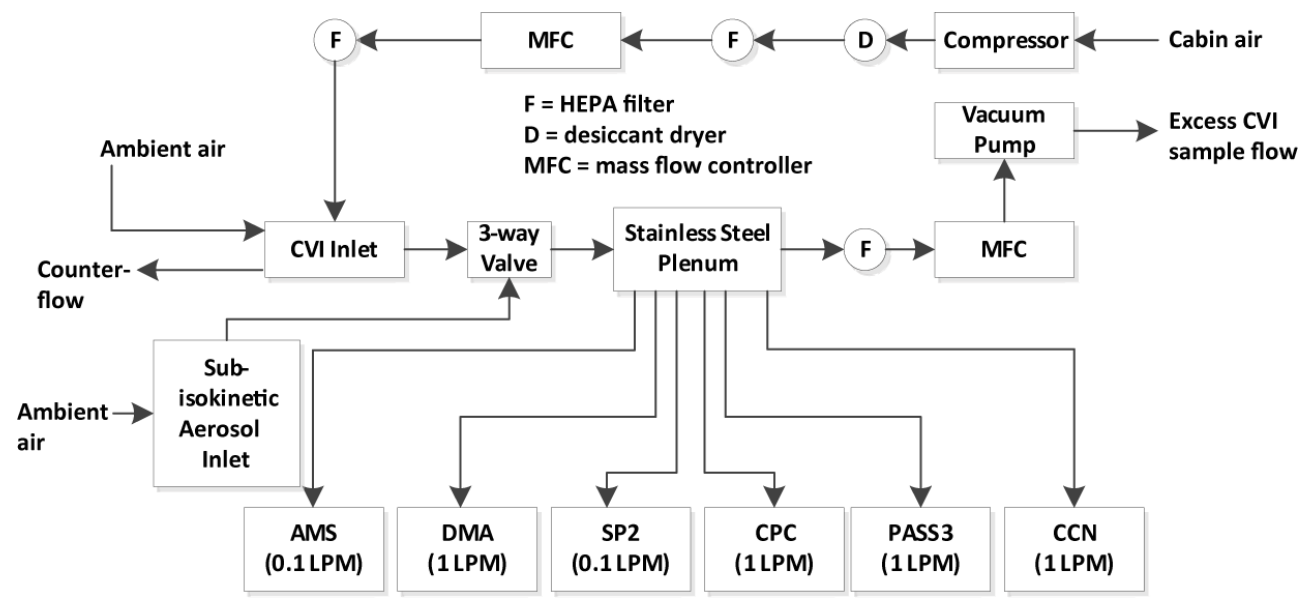

Fig. 5. Schematic of the sample air flow path through both the sub-isokinetic aerosol inlet (clear air sampling) and the CVI (in-cloud sampling) on the CIRPAS Twin Otter during the 2011 E-PEACE experiment. Six instruments characterised aerosol physicochemical properties downstream of the CVI inlet with their respective flow rates shown (total $=4.21 \mathrm{~min}^{-1}$ ). As the total sample flow rate provided was $151 \mathrm{~min}^{-1}$, the excess sample flow $\left(10.81 \mathrm{~min}^{-1}\right)$ was diverted out of the aircraft by a vacuum pump.

Variances between predicted and measured cut sizes are accounted for by adjusting the impaction starting point, $L_{\text {cur }}$. Previous cut size prediction methods have defined $L_{\text {cur }}$ as a constant $\left(g(r)\right.$ or $\left.C_{1}\right)$ multiplied by the outer probe radius, used to account for streamline curvature of air near the orifice of the probe (Noone et al., 1988; Anderson et al., 1993). Data obtained during the wind tunnel experiments were used to predict an average $C_{1}$ value of 1.25 over the range of counter-flow rates from $1-81 \mathrm{~min}^{-1}$ and air speeds from 50 $100 \mathrm{~m} \mathrm{~s}^{-1}$. Over this range, the $C_{1}$ value has a mean error of $1.7 \%$ for the conditions tested. Individual percentage differences between the predicted and measured values, for each of the six conditions tested, are reported in Table 1.

Characterisation in the wind tunnel also included evaluating particle size-dependent losses in the CVI body, mainly as a result of inertial deposition. Losses were evaluated by comparing size distributions obtained while sampling through different portions of the sampling train to the distribution of glass beads measured by the APS with no CVI tip assembly installed in the wind tunnel. Experiments were performed to isolate losses for separate segments of the wind tunnel sampling train. Particle transmission was measured through a long sampling tube labelled 3 in Fig. 2, followed by examining losses through the sample expansion section coupled to the long sampling tube (Segments 2 and 3 in Fig. 2). Finally, a comparison was made to a sample from the combined segments (Segments 1, 2 and 3 in Fig. 2). From this, losses in Segments 1 and 2 (Fig. 2) were individually determined. It should be noted that the wind tunnel sampling configuration differs from the configuration of the inlet as installed on an aircraft. Only losses in Segments 1 and 2, which correspond to Segments B and C (Fig. 1), are relevant to the aircraft installation. These losses are presented in Fig. 4, showing each segment's individual contribution and the combined effect. Tubing prior to the expansion is shown to be a larger source for particle losses via turbulent deposition as compared to the expansion. At the expected cut size of $11 \mu \mathrm{m}$ during E-PEACE the total losses amount to approximately $57 \%$ and increase to $72 \%$ at a particle diameter of $20 \mu \mathrm{m}$. It is noted that the tubing prior to the expansion is interchangeable, and losses can be significantly reduced by using a shortened tube. Ongoing work is addressing these 

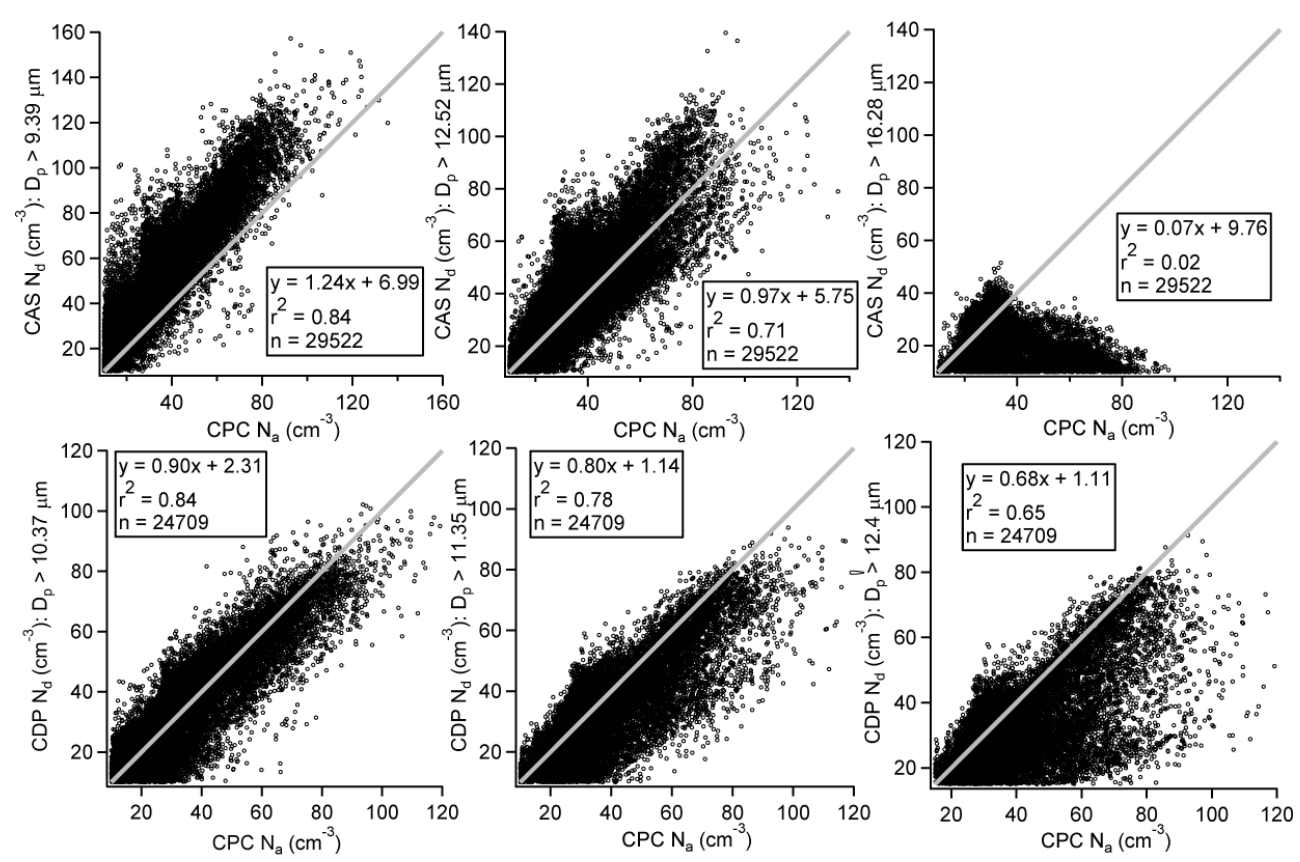

Fig. 6. Comparison of corrected total particle concentration $\left(N_{\mathrm{a}}\right)$ measured behind the CVI by a CPC and total cloud drop concentration $\left(N_{\mathrm{d}}\right)$ measured by two independent cloud probes (CDP and CAS). For both cloud probes, $N_{\mathrm{d}}$ is reported above three different minimum drop sizes around the expected cut size $(\sim 11 \mu \mathrm{m})$ of the CVI at $50 \mathrm{~m} \mathrm{~s}^{-1}$ for the usual add-flow rate applied $\left(\sim 161 \mathrm{~min}^{-1}\right)$ based on wind tunnel results. Data are shown when the in-cloud liquid water content exceeded $0.05 \mathrm{~g} \mathrm{~m}^{-3}$, when the aircraft speed was between $45-60 \mathrm{~m} \mathrm{~s}^{-1}$, and when the add-flow rate was between $16-171 \mathrm{~min}^{-1}$. The gray shaded lines signify the 1-to- 1 line. The reason the slope of the top right panel is much lower than the rest is that the majority of the sampled cloud drop number concentrations were typically at lower diameters.

losses. However, the results in Fig. 4 are critical for interpreting the E-PEACE field data, especially for validating the cut size measurements from the wind tunnel testing.

\section{Field deployment and first results}

The CVI was deployed on the Center for Interdisciplinary Remotely-Piloted Aircraft Studies (CIRPAS) Twin Otter during the 2011 E-PEACE field study off the central coast of California. E-PEACE consisted of 30 research flights to study aerosol-radiation-cloud-precipitation interactions over the eastern Pacific Ocean during the summertime when stratocumulus cloud decks are persistent. The domain of the flights ranged between $34^{\circ} \mathrm{N}-40^{\circ} \mathrm{N}$ and $121.5^{\circ} \mathrm{W}-125^{\circ} \mathrm{W}$. Nine of the Twin Otter flights were coordinated with the R/V Point Sur, which generated smoke on each of these days to allow the aircraft to study the effects of a known source of aerosol on cloud microphysical and macrophysical properties. A comprehensive description of this field study is forthcoming.

Six different instruments conducted measurements downstream of the CVI in stratocumulus clouds during E-PEACE (Fig. 5). A three-way valve was used to cycle these six instruments between the CVI in cloud and a sub-isokinetic aerosol inlet out of cloud (Hegg et al., 2005). When sampling was conducted through the CVI in cloud, the total flow required by the downstream instruments was typically near $4.21 \mathrm{~min}^{-1}$ with the CVI sample-flow MFC controlling the remaining $10.81 \mathrm{~min}^{-1}$. Minor variations existed in the total sample flow rate based on fluctuations in flow requirements among the various instruments downstream of the CVI. When the instruments downstream of the CVI were not sampling from the CVI sample-flow stream, the MFC controlled the full $151 \mathrm{~min}^{-1}$ through the sample stream. The instruments included a condensation particle counter (CPC; TSI Model 3010) to quantify total aerosol concentration $\left(N_{\mathrm{a}}\right)$. Aerosol size distribution data were obtained by a cylindrical scanning differential mobility analyser (DMA; TSI Model 3081) coupled to a condensation particle counter (CPC; TSI Model 3010). Aerosol particles were dried prior to entering the DMA for sizing. Aerosol absorption and scattering coefficients were measured using a three-wavelength Photoacoustic Soot Spectrometer (PASS-3; Droplet Measurement Technologies). A continuous flow thermal gradient cloud condensation nuclei counter ( $\mathrm{CCNc}$, Droplet Measurement Technologies Inc.; Roberts and Nenes, 2005) was used to quantify the number of particles that activated at supersaturations ranging from $0.2 \%$ to $0.8 \%$. Black carbon (BC) mass measurements were obtained using a single particle soot photometer instrument (SP2; Droplet Measurement Technologies) (Schwarz et al., 2006; Metcalf et al., 2012). 
Measurements of inorganic mass (sulfate, nitrate, ammonium) and total non-refractory organic mass were obtained with a compact Time of Flight Aerosol Mass Spectrometer (Aerodyne C-ToF-AMS) (Drewnick et al., 2005). A comprehensive analysis of the detailed measurements of droplet residual particle properties will be addressed in a subsequent study.

Critical to the examination of field data is the quantification of the "enhancement factor" (EF) as a result of the ambient aerosol concentration being concentrated in the CVI inlet according to the following equation:

$\mathrm{EF}=\frac{A_{\text {tip }} V_{\text {plane }}}{q_{\text {sample }}}$

where: $A_{\text {tip }}$ is the area of the inlet tip where drops enter, $V_{\text {plane }}$ is aircraft velocity, and $q_{\text {sample }}$ is the volumetric flow rate of sampled air in the CVI inlet. $A_{\text {tip }}$ is $1.67 \times 10^{-5} \mathrm{~m}^{2}$, $q_{\text {sample }}$ is $151 \mathrm{~min}^{-1}$, and the aircraft velocity was usually near $50 \mathrm{~m} \mathrm{~s}^{-1}$. This air velocity, which was tested in the wind tunnel experiments, coincides with an EF of 3.28.

To identify whether there was any contamination of small particles through the CVI, the inlet was operated for small periods of time during some flights in clear air just as it would be in cloud. To ensure the aircraft was in clear air for this analysis, data were used when the cloud liquid water content (LWC), measured by a PVM-100 probe (Gerber et al., 1994), was less than $0.01 \mathrm{~g} \mathrm{~m}^{-3}$. When applying an add-flow ranging between $16-191 \mathrm{~min}^{-1}$, the CPC concentration in clear air $\left(\mathrm{LWC}=0.002 \pm 0.009 \mathrm{~g} \mathrm{~m}^{-3}\right.$ ) was $0.08 \pm 0.09 \mathrm{~cm}^{-3}$. The ratio of the $\mathrm{CPC}$ concentration downstream of the CVI relative to an identical instrument sampling simultaneously downstream of a sub-isokinetic inlet was $0.0001 \pm 0.0002$, indicating that instances of particle breakthrough and small particle contamination were absent.

Prior to E-PEACE, test flights were conducted to determine the flow angle at the location of the CVI intake. The location was only a short distance forward of the port wing root. Significant angles between the oncoming air flow and the CVI inlet will increase the likelihood of droplet impaction and shatter on inlet surfaces. A Rosemount 858 flow angle probe indicated a $10^{\circ}$ up-wash at that location during flight, and flow visualisation using yarn taped to the probe's tip verified this angle. To minimize the chance of flow separation in the sampling inlet, and possible particle losses, the CVI probe was angled into the flow and mounted on the airplane with a $10^{\circ}$ downward tilt. The inlet tip-to-fuselage distance of $178 \mathrm{~mm}$ places the sampling stream outside the maximum shadow zone of $160 \mathrm{~mm}$ for the CIRPAS Twin Otter aircraft. The maximum shadow zone is calculated as $20 \%$ of the aircraft's fuselage radius (King, 1984).

Critical to the characterisation of the field performance of the CVI is the comparison of particle number concentration $\left(N_{\mathrm{a}}\right)$ measured by the CPC downstream of the CVI to in situ measurements of cloud drop concentration $\left(N_{\mathrm{d}}\right)$. For the latter measurement, data were obtained using a Cloud

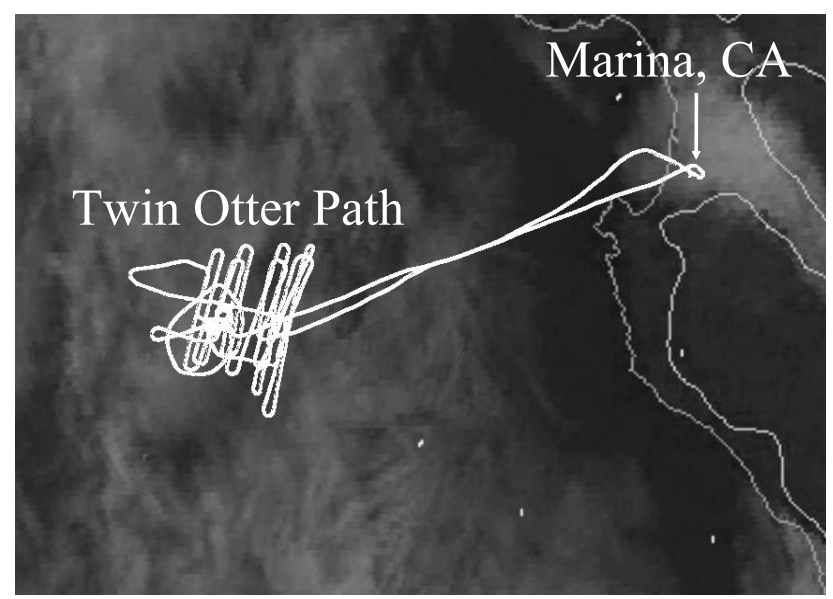

Fig. 7. GOES-11 visible satellite imagery at 18:00 UTC on 16 July 2011 with the superposition of the CIRPAS Twin Otter, which was based in Marina, California. The high density of flight track points to the far west coincides with when the aircraft was probing the smoke plume generated by the R/V Point Sur ship. The corresponding time series of aircraft data is shown in Fig. 8 with aerosol size distribution and composition data shown in Fig. 9.

and Aerosol Spectrometer (CAS; $D_{\mathrm{p}} \sim 1-55 \mu \mathrm{m}$; Droplet Measurement Technologies, Inc.; Baumgardner et al., 2001) and a Cloud Droplet Probe (CDP; $D_{\mathrm{p}} \sim 1-51 \mu \mathrm{m}$; Droplet Measurement Technologies, Inc.; Lance et al., 2010). These probes were calibrated during the E-PEACE campaign using monodisperse polystyrene and glass beads. Uncertainties in counting and sizing associated with these instruments have been documented elsewhere (e.g., Baumgardner et al., 2001; Conant et al., 2004; Lance et al., 2010). As noted below, neither of the probes have size bin limits that directly match the CVI cut size of $11 \mu \mathrm{m}$, therefore, a purpose of the following analysis is to examine relative changes in the ratio of $N_{\mathrm{a}}$ to $N_{\mathrm{d}}$ when integrating drop distributions over different drop size ranges. CVI data are presented for the first 11 flights (8 July-23 July) since both cloud probes were operational during this time range. Periods with extensive drizzle, as identified with a Cloud Imaging Probe (CIP; $D_{\mathrm{p}} \sim 25-$ $1600 \mu \mathrm{m})$ were omitted for this analysis owing to potential artifacts associated with the breakup of large drops (Weber et al., 1998). The comparison involved applying the EF to the CPC data and the size-dependent transmission efficiency results in Fig. 4 to the cloud probe data to assess the level of agreement between $N_{\mathrm{a}}$ and $N_{\mathrm{d}}$. Figure 6 summarises the comparison of $N_{\mathrm{a}}$ to $N_{\mathrm{d}}$, where the latter was quantified using a variety of minimum drop sizes smaller and larger than the cut size identified from the wind tunnel experiments. It is noted that the CAS instrument has larger bin widths (i.e., bin boundaries of $9.39,12.52$, and $16.28 \mu \mathrm{m}$ ) around the vicinity of the wind tunnel CVI cut size $(11 \mu \mathrm{m})$ relative to the CDP (i.e., bin boundaries of $10.37,11.35,12.4 \mu \mathrm{m}$ ). The analysis was conducted for the following conditions: (i) LWC 


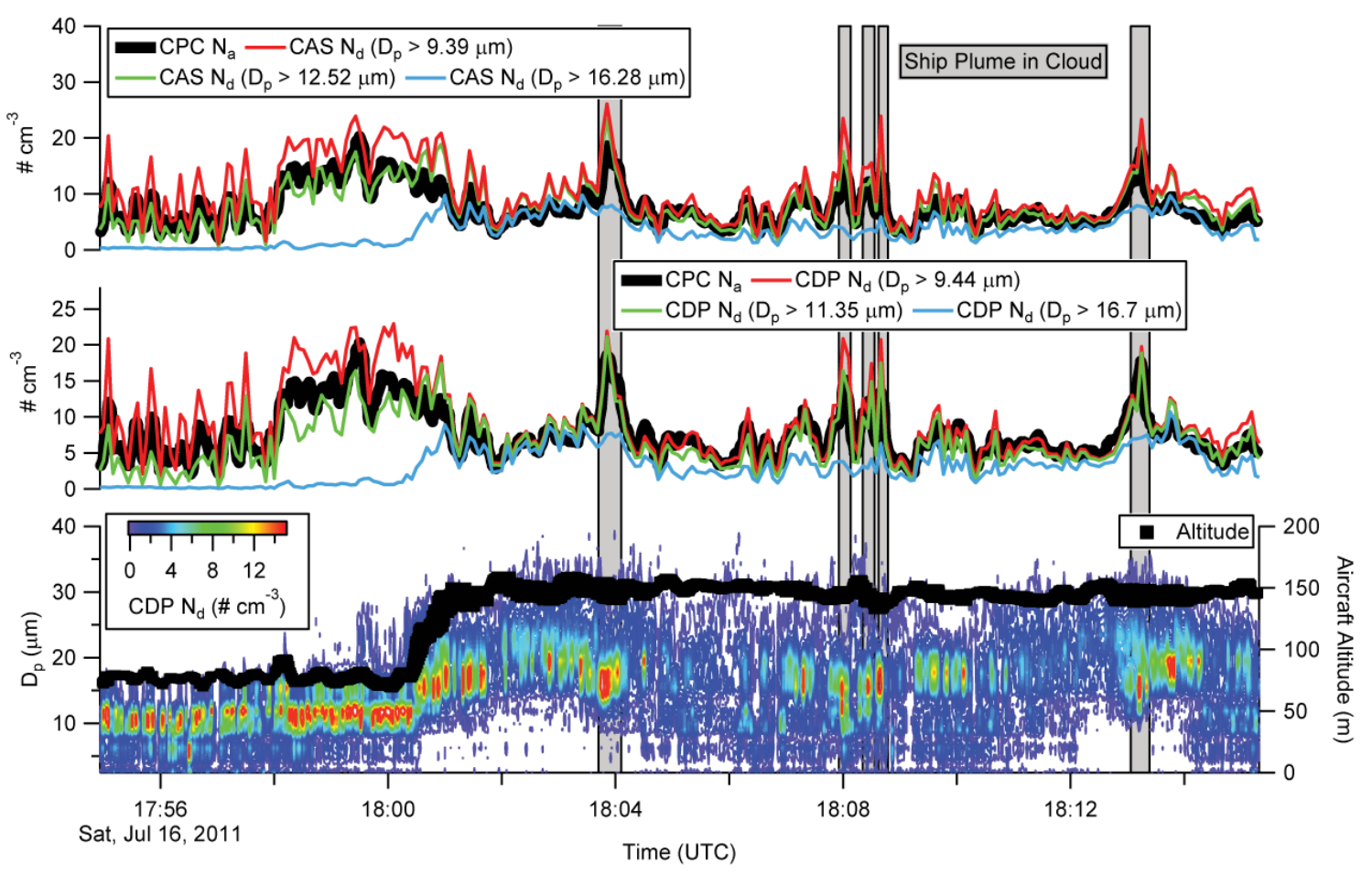

Fig. 8. Time series of aircraft data collected during Flight 6 of the 2011 E-PEACE campaign on 16 July 2011. The 20-min time segment coincides with when the Twin Otter was flying in a stratocumulus cloud deck of the coast of Monterey, California. This flight was coordinated with the R/V Point Sur, which generated smoke that influenced the cloud in the several gray shaded regions of the time series via enhancements in drop concentration and reductions in drop size. The total particle concentration $\left(N_{\mathrm{a}}\right)$ measured behind the CVI by a CPC (with enhancement factor, $\sim 3.3$, applied) is compared to total cloud drop concentration $\left(N_{\mathrm{d}}\right)$ measured by two independent probes, where $N_{\mathrm{d}}$ is integrated above three different diameters to further constrain the CVI cut size diameter. Size-dependent transmission efficiency losses from Fig. 4 are applied to the $N_{\mathrm{d}}$ data. The aircraft altitude marker size is proportional to LWC (range $\sim 0.05-0.30 \mathrm{~g} \mathrm{~m}^{-3}$ ).

greater than $0.05 \mathrm{~g} \mathrm{~m}^{-3}$ to ensure the aircraft was in cloud; (ii) aircraft speeds between $45-60 \mathrm{~m} \mathrm{~s}^{-1}$ to allow for a meaningful comparison with the wind tunnel results at $50 \mathrm{~m} \mathrm{~s}^{-1}$; and (iii) the add-flow rate was either 16 or $171 \mathrm{~min}^{-1}$. The agreement between $N_{\mathrm{a}}$ and $N_{\mathrm{d}}$ is best when the CAS drop distributions were integrated above $12.52 \mu \mathrm{m}\left(r^{2}=0.71\right)$ and when the CDP distributions were integrated above $10.37 \mu \mathrm{m}$ $\left(r^{2}=0.84\right)$. The slopes of $N_{\mathrm{a}}$ to $N_{\mathrm{d}}$ plots were closest to unity $(0.90-0.97)$ for these two conditions with decreasing values when integrating the cloud drop distribution above larger sizes, indicating that the CVI cut size was close to $11 \mu \mathrm{m}$. To assess the sensitivity of the Fig. 6 results to the transmission efficiency results, an analogous analysis was done while ignoring the correction to the cloud probe $N_{\mathrm{d}}$ values to account for the transmission efficiency (Fig. 5). The increase in the Fig. 6 slopes ranges between factors of 2.49-3.86.

One case flight is examined in greater detail to examine the temporal trends in $N_{\mathrm{a}}$ and $N_{\mathrm{d}}$ in cloud. The focus of this analysis is Research Flight 6 on 16 July 2011, which was a flight coordinated between the Twin Otter and the R/V Point Sur. The latter was generating smoke with an onboard smoke generator, and the aircraft probed the properties of the smoke both below cloud and in cloud. The flight tracks of the Twin Otter are shown in Fig. 7 superimposed on GOES-11 visible satellite imagery to show the structure of the clouds during the period of the flight. The aircraft conducted detailed measurements of aerosol properties below the cloud deck, within the cloud at different altitudes, and above the cloud deck. Figure 8 shows a representative 20 min flight leg when the Twin Otter was sampling in cloud, during which time the aircraft sampled the ship smoke in cloud numerous times. Based on a threshold LWC value of $0.05 \mathrm{~g} \mathrm{~m}^{-3}$, this particular cloud deck had a base and top of approx. $70 \mathrm{~m}$ and $200 \mathrm{~m}$, respectively. During the flight leg shown, the aircraft ascended from a region slightly above the bases to near the middle of the cloud deck, which is reflected in the increase in droplet size (Fig. 8; bottom panel). The $N_{\mathrm{a}}$ measurement downstream of the CVI is shown to exhibit the same temporal behaviour as $N_{\mathrm{d}}$ measured by the CAS and CDP, when the size distributions of the two latter cloud probes were integrated at or below the expected cut size of the CVI $(\sim 11 \mu \mathrm{m})$. When the aircraft flew in cloud regions influenced by the ship smoke, both $N_{\mathrm{a}}$ and $N_{\mathrm{d}}$ levels were enhanced with a reduction in drop size, which is consistent with the Twomey Effect (Twomey, 1974). Based on CDP drop distributions integrated above $10.37 \mu \mathrm{m}$, the fraction of 


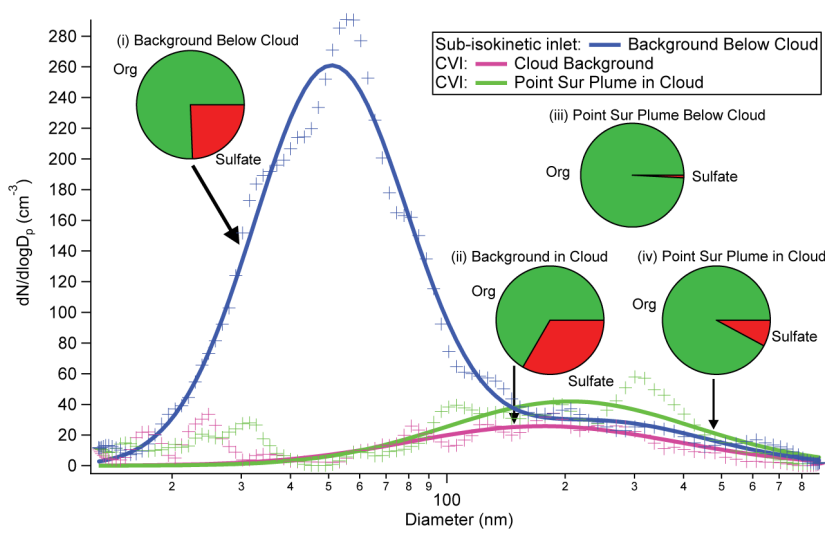

Fig. 9. DMA size distribution and AMS chemical composition measurements during Flight 6 from Figs. 7 and 8. The DMA data collected downstream of a sub-isokinetic inlet below cloud were fit to a two-term log-normal function while the size distributions downstream the CVI were fit to a single-term log-normal function for data greater than $50 \mathrm{~nm}$ diameter. The DMA raw data are also included for each of the log-normal fits. Only sulfate and non-refractory organics were observed above detection limits by the AMS, and their relative mass concentrations are depicted in the pie charts for four different conditions: (i-ii) background marine aerosol below cloud and in cloud behind the CVI; (iii-iv) R/V Point Sur smoke below cloud and in cloud behind the CVI. DMA data are not available for the R/V Point Sur smoke below cloud since those crossings were too narrow for an entire DMA scan $(\sim 110 \mathrm{~s})$ to capture.

drops larger than the CVI cut size for the entire duration of Fig. 8, which is representative of conditions experienced during E-PEACE, was $78.2 \pm 18.9 \%$, where the lowest fractions are associated with sampling immediately above cloud base (17:54-18:00 UTC: $58.2 \pm 19.2 \%$ ) as compared to sampling near the middle and below the top of the cloud deck (18:0018:15 UTC: $86.2 \pm 11.2 \%$ ). Ship plume influenced regions of clouds are associated with reductions in the sampled drop fraction owing to the reduction in droplet size as shown in Fig. 8.

Two critical aspects of the CVI performance during EPEACE included the ability to avoid organic contamination and accessibility to the interior of the inlet probe. There was no indication of organic contamination from the inlet during E-PEACE. AMS measurements of non-refractory organics in droplet residual particles during clean marine background conditions were typically below the AMS organic detection limit of $0.1 \mu \mathrm{g} \mathrm{m}^{-3}$. Increases in the AMS organic mass concentration corresponded with enhancements in other measurements indicating signs of increasing pollution (e.g., CPC, CDP, CAS, and other aerosol/cloud instruments); therefore, E-PEACE CVI measurements indicate that organic signals are a measurement of cloud nuclei chemistry and are uninfluenced by artifacts associated with the inlet material of construction. During the E-PEACE campaign, the CVI tip was removed, inspected for material deposition, and cleaned a number of times. Towards the end of the E-PEACE campaign, the tip portion of the inlet was switched with another modified version to alter cut size limits. The process of handling, cleaning and even replacing the interior portion of the inlet was fairly quick and straightforward.

An example of aerosol composition measurements downstream of the CVI is shown in Fig. 9. Four representative AMS mass fraction pie charts are shown to represent the following from Flight 6: background marine aerosol below cloud; background in cloud (CVI); R/V Point Sur ship smoke below cloud; and R/V Point Sur ship smoke in cloud (CVI). Only sulfate and organic contributions are shown since the other non-refractory constituents (i.e., ammonium, chloride, nitrate) were below detection limits. Organics were the dominant non-refractory component of the sub-micrometer aerosol, and this is especially the case for the R/V Point Sur smoke, which was nearly entirely organic ( $\sim 99 \%)$ when sampled below cloud during this flight. The droplet residual samples examined during the time when the R/V Point Sur smoke was intercepted in cloud were mainly of organic nature $(\sim 92 \%)$, as compared to the background cloud conditions $(\sim 67 \%)$.

Figure 9 shows raw and fitted size distribution data from a scanning differential mobility analyser during the same sampling periods used to generate the AMS pie charts. The background aerosol below cloud, sampled from the sub-isokinetic inlet, was fit to a two-term lognormal function. The size distributions obtained behind the CVI were considerably noisier, owing to a dramatic reduction in raw particle counts in the instrument. These size distributions were fit to a single lognormal function using the size distribution data greater than $50 \mathrm{~nm}$ diameter only, because the existence of a particle mode at these sizes can be confirmed by the scattering channels on the SP2 (data not shown). Therefore, caution should be used when viewing data at sub- $50 \mathrm{~nm}$ as these data are subject to larger correction factors in the DMA data inversion owing to diffusional losses in the instrument. The R/V Point Sur smoke crossings below cloud were sufficiently narrow such that an entire DMA scan $(\sim 110 \mathrm{~s})$ did not properly capture the size distribution of this source and, thus, only one average distribution is presented. The background sub-cloud size distribution exhibits a bimodal character with a sub- $100 \mathrm{~nm}$ mode and a larger mode, indicative of cloudprocessed aerosol. The single mode fits to the droplet residual size distributions peak at approximately $200 \mathrm{~nm}$ diameter, indicating that the larger of the two modes below cloud was most effective at activating into droplets (at least for droplets larger than the cut size of $11 \mu \mathrm{m}$ ). It is likely that smaller particles may have activated into drops that could not be sampled owing to being smaller than the inlet cut size. The raw data show that the number concentrations of droplet residual particles in the mode larger than $100 \mathrm{~nm}$ are expectedly higher in the plume-influenced regions of clouds. More detailed results of the physicochemical properties of droplet residual particles from the E-PEACE study will be forthcoming. 


\section{Conclusions}

A new CVI inlet has been characterised using wind tunnel experiments and deployed on the CIRPAS Twin Otter for 30 flights during the 2011 E-PEACE field campaign. With straightforward modifications, the inlet can also be deployed at ground or mountaintop sites to sample fog and orographic clouds. With a fixed sample flow rate of $151 \mathrm{~min}^{-1}$, the wind tunnel experiments explored a range of add-flow rates $\left(16-231 \mathrm{~min}^{-1}\right)$ and air velocities $\left(50-100 \mathrm{~m} \mathrm{~s}^{-1}\right)$ to obtain inlet cut sizes between 8.7-13.1 $\mu \mathrm{m}$. Calculated cut sizes from aerodynamic drag theory agree with measured values to within $13 \%$. When applying size-dependent transmission efficiency results from the wind tunnel to aircraft data, there was good agreement between particle concentration $\left(N_{\mathrm{a}}\right)$ measurements downstream of the CVI and cloud drop concentrations $\left(N_{\mathrm{d}}\right)$ measured by two independent cloud probes. When integrating the drop size distributions above a diameter close to the expected $11 \mu \mathrm{m}$ cut size (based on wind tunnel testing), slopes from $N_{\mathrm{d}}-N_{\mathrm{a}}$ plots were $0.90-0.97$ and correlation coefficients $\left(r^{2}\right)$ were $0.71-0.84$. Representative data from a case study flight show excellent temporal agreement between $N_{\mathrm{a}}$ and $N_{\mathrm{d}}$, especially when a smoke plume from a ship was intercepted in cloud. This resulted in sudden enhancements in drop concentration and reductions in drop size. Size distribution measurements of droplet residual particles during this flight show that the modal diameter of particles activated into drops was approximately $200 \mathrm{~nm}$ both in and out of the smoke. Aerosol composition measurements from an AMS indicate that the majority of the submicrometer non-refractory mass was from organic species, with the remaining constituent being sulfate. No indication of organic contamination from the inlet itself was found and there was easy access to the interior of the inlet for cleaning and replacement of the inlet tip. Furthermore, no evidence of particle breakthrough or small particle contamination was observed during CVI sampling during E-PEACE.

Acknowledgements. This work was funded by an ONR DURIP grant (N00014-11-1-0783), an ONR YIP award (N00014-10-10811), ONR grant N00014-10-1-0200, NSF grants AGS-1008848 and AGS1013423, and Sea Spray Research, Inc. The authors acknowledge Cynthia Twohy and an anonymous reviewer for helpful comments. The authors gratefully acknowledge the crew of both the CIRPAS Twin Otter and the R/V Point Sur.

Edited by: D. Toohey

\section{References}

Anderson, T. L., Charlson, R. J., and Covert, D. S.: Calibration of a counterflow virtual impactor at aerodynamic diameters from 1 to $15 \mu \mathrm{m}$, Aerosol Sci. Tech., 19, 317-329, 1993.

Baumgardner, D. and Huebert, B.: The Airborne Aerosol Inlet Workshop - Meeting Report, J. Aerosol Sci., 24, 835-846, 1993.
Baumgardner, D., Jonsson, H., Dawson, W., O’Connor, D., and Newton, R.: The cloud, aerosol and precipitation spectrometer: A new instrument for cloud investigations, Atmos. Res., 59-60, 251-264, 2001.

Berg, L. K., Berkowitz, C. M., Ogren, J. A., Hostetler, C. A., Ferrare, R. A., Dubey, M. K., Andrews, E., Coulter, R. L., Hair, J. W., Hubbe, J. M., Lee, Y. N., Mazzoleni, C., Olfert, J., and Springston, S. R.: Overview of the Cumulus Humilis Aerosol Processing Study, B. Am. Meteorol. Soc., 90, 1653-1667, 2009.

Conant, W. C., VanReken, T. M., Rissman, T. A., Varutbangkul, V., Jonsson, H. H., Nenes, A., Jimenez, J. L., Delia, A. E., Bahreini, R., Roberts, G. C., Flagan, R. C., and Seinfeld, J. H.: Aerosolcloud drop concentration closure in warm cumulus, J. Geophys. Res., 109, D13204, doi:10.1029/2003JD004324, 2004.

Drewnick, F., Hings, S. S., DeCarlo, P., Jayne, J. T., Gonin, M., Fuhrer, K., Weimer, S., Jimenez, J. L., Demerjian, K. L., Borrmann, S., and Worsnop, D. R.: A new time-of-flight aerosol mass spectrometer (TOF-AMS) - Instrument description and first field deployment, Aerosol Sci. Tech., 39, 637-658, 2005.

Gerber, H., Arends, B. G., and Ackerman, A. S.: New microphysics sensor for aircraft use, Atmos. Res., 31, 235-252, 1994.

Hallberg, A., Noone, K. J., Ogren, J. A., Svenningsson, I. B., Flossmann, A., Wiedensohler, A., Hansson, H. C., Heintzenberg, J., Anderson, T. L., Arends, B. G., and Maser, R.: Phase partitioning of aerosol particles in clouds at Kleiner Feldberg, J. Atmos. Chem., 19, 107-127, 1994.

Hallberg, A., Noone, K. J., and Ogren, J. A.: Aerosol particles and clouds: which particles form cloud-droplets?, Tellus B, 50, 59$75,1998$.

Hayden, K. L., Macdonald, A. M., Gong, W., Toom-Sauntry, D., Anlauf, K. G., Leithead, A., Li, S.-M., Leaitch, W. R., and Noone, K.: Cloud processing of nitrate, J. Geophys. Res., 113, D18201, doi:10.1029/2007JD009732, 2008.

Hegg, D. A., Covert, D. S., Jonsson, H., and Covert, P. A.: Determination of the transmission efficiency of an aircraft aerosol inlet, Aerosol Sci. Tech., 39, 966-971, 2005.

Hermann, M., Stratmann, F., Wilck, M., and Wiedensohler, A.: Sampling characteristics of an aircraft-borne aerosol inlet system, J. Atmos. Ocean Tech., 18, 7-19, 2001.

Hudson, J. G.: Cloud condensation nuclei near marine cumulus, J. Geophys. Res., 98, 2693-2702, 1993.

Hudson, J. G. and Frisbie, P. R.: Cloud condensation nuclei near marine stratus, J. Geophys. Res., 96, 20795-20808, 1991.

Huebert, B. J., Lee, G., and Warren, W. L.: Airborne aerosol inlet passing efficiency measurement, J. Geophys. Res., 95, 16369$16381,1990$.

King, W. D.: Air flow and particle trajectories around aircraft fuselages, I: Theory, J. Atmos. Ocean. Tech., 1, 5-13, 1984.

Lance, S., Brock, C. A., Rogers, D., and Gordon, J. A.: Water droplet calibration of the Cloud Droplet Probe (CDP) and inflight performance in liquid, ice and mixed-phase clouds during ARCPAC, Atmos. Meas. Tech., 3, 1683-1706, doi:10.5194/amt3-1683-2010, 2010.

Laucks, M. L. and Twohy, C. H.: Size-dependent collection efficiency of an airborne counterflow virtual impactor, Aerosol Sci. Tech., 28, 40-61, 1998.

Lin, H. and Heintzenberg, J.: A theoretical-study of the counterflow virtual impactor, J. Aerosol Sci., 26, 903-914, 1995. 
Metcalf, A. R., Craven, J. S., Ensberg, J. J., Brioude, J., Angevine, W., Sorooshian, A., Duong, H. T., Jonsson, H., Flagan, R. C., and Seinfeld, J. H.: Black carbon aerosol over the Los Angeles Basin during CalNex, J. Geophys. Res., 117, D00V13, doi:10.1029/2011JD017255, 2012.

Noone, K. J., Ogren, J. A., Heintzenberg, J., Charlson, R. J., and Covert, D. S.: Design and calibration of a counterflow virtual impactor for sampling of atmospheric fog and cloud-droplets, Aerosol Sci. Tech., 8, 235-244, 1988.

Ogren, J. A., Heintzenberg, J., and Charlson, R. J.: In-situ sampling of clouds with a droplet to aerosol converter, Geophys. Res. Lett., 12, 121-124, 1985.

Ogren, J. A., Heintzenberg, J., and Charlson, R. J.: Virtual impactor, US Patent No. 4,689,052, 1987.

Ostrom, E., Noone, K. J., and Pockalny, R. A.: Cloud-droplet residual particle microphysics in marine stratocumulus clouds observed during the Monterey Area Ship Track experiment, J. Atmos. Sci., 7, 2671-2683, 2000.

Roberts, G. C. and Nenes, A.: A continuous-flow streamwise thermal-gradient $\mathrm{CCN}$ chamber for atmospheric measurements, Aerosol Sci. Tech., 39, 206-221, doi:10.1080/027868290913988, 2005.

Schwarz, J. P., Gao, R. S., Fahey, D. W., Thomson, D. S., Watts, L. A., Wilson, J. C., Reeves, J. M., Darbeheshti, M., Baumgardner, D. G., Kok, G. L., Chung, S. H. Schulz, M., Hendricks, J., Lauer, A., Karcher, B., Slowik, J. G., Rosenlof, K. H., Thompson, T. L., Langford, A. O., Loewenstein, M., and Aikin, K. C.: Single-particle measurements of midlatitude black carbon and light-scattering aerosols from the boundary layer to the lower stratosphere, J. Geophys. Res., 111, D16207, doi:10.1029/2006JD007076, 2006.

Schwarzenböck, A. and Heintzenberg, J.: Cut size minimisation and cloud element break-up in a ground-based CVI, J. Aerosol Sci., 31, 477-489, 2000.
Sellegri, K., Laj, P., Dupuy, R., Legrand, M., Preunkert, S., and Putaud, J. P.: Size-dependent scavenging efficiencies of multicomponent atmospheric aerosols in clouds, J. Geophys. Res., 108, 4334, doi:10.1029/2002JD002749, 2003.

Sorooshian, A., Brechtel, F. J., Ma, Y. L., Weber, R. J., Corless, A., Flagan, R. C., and Seinfeld, J. H.: Modeling and characterisation of a particle-into-liquid sampler (PILS), Aerosol Sci. Tech., 40, 396-409, doi:10.1080/02786820600632282, 2006a.

Sorooshian, A., Varutbangkul, V., Brechtel, F. J., Ervens, B., Feingold, G., Bahreini, R., Murphy, S. M., Holloway, J. S., Atlas, E. L., Buzorius, G., Jonsson, H., Flagan, R. C., and Seinfeld, J. H. : Oxalic acid in clear and cloudy atmospheres: Analysis of data from International Consortium for Atmospheric Research on Transport and Transformation 2004, J. Geophys. Res., 111, D23S45, doi:10.1029/2005JD006880, 2006b.

Sorooshian, A., Murphy, S. M., Hersey, S., Bahreini, R., Jonsson, H., Flagan, R. C., and Seinfeld, J. H.: Constraining the contribution of organic acids and AMS $\mathrm{m} / \mathrm{z} 44$ to the organic aerosol budget: On the importance of meteorology, aerosol hygroscopicity, and region, Geophys. Res. Lett., 37, L21807, doi:10.1029/2010GL044951, 2010.

Twohy, C. H.: Model calculations and wind tunnel testing of an isokinetic shroud for high-speed sampling, Aerosol Sci. Tech., 29, 261-280, 1998.

Twohy, C. H., Clarke, A. D., Warren, S. G., Radke, L. F., and Charlson, R. J.: Light absorbing material extracted from cloud-droplets and its effect on cloud albedo, J. Geophys. Res., 94, 8623-8631, 1989.

Twomey, S.: Pollution and planetary albedo, Atmos. Environ., 8, 1251-1256, 1974.

Weber, R. J., Clarke, A. D., Litchy, M., Li, J., Kok, G., Schillawski, R. D., and McMurry, P. H.: Spurious aerosol measurements when sampling from aircraft in the vicinity of clouds, J. Geophys. Res., 103, 28337-28346, 1998. 